(Journal of Civil Engineering, Building and Transportation)

\title{
Analisa Nilai Kohesi dan Sudut Geser Tanah Lempung yang Distabilisasi dengan Arang Kayu
}

\section{Analysis of Cohesion Values and Slope of Clay Lands that are Stabilized with Wood Charcoal}

\author{
Rini \& Melloukay Ardan \\ Program Studi Teknik Sipil, Fakultas Teknik, Universitas Medan Area, Indonesia \\ *Coresponding Email: rinitapten@yahoo.co.id
}

\section{Abstrak}

Penelitian ini dilakukan dengan tujuan menganalisa nilai kohesi dan sudut geser tanah lempung yang dicampur dengan arang kayu.. Uji kuat geser tanah yang dilakukan adalah kuat geser langsung (direct shear test) dengan persentase penambahan arang kayu sebesar 4\%,6\%, 8\%, dan 10\%. Dari hasil pengujian batas konsistensi tanah yang dicampur dengan arang dapat menurunkan nilai batas cair tanah dan menaikkan batas plastis tanah sehingga indeks plastis tanah menjadi menurun. Hal ini menunjukkan adanya perbaikkan sifat tanah. Sedangkan hasil dari pengujian kuat geser tanah dengan penambahan campuran arang pada tanah lempung nilai kohesi tanah mengalami kenaikkan dan pada sudut geser tanah mengalami penurunan. Hal ini dapat meningkatkan kuat geser tanah lempung. Dengan menambahkan arang sebagai bahan stabilisasi pada tanah lempung yang ditinjau dari kuat geser tanah maka arang dapat digunakan sebagai bahan stabilisasi untuk mengurangi terjadinya keruntuhan pada tanah lempung.

Kata Kunci: Tanah Lempung, Direct Shear Test, Stabilisasi Tanah, Kohesi

\begin{abstract}
This research was conducted with the purpose of dealing with wood charcoal. The strong test is direct shear test with $4 \%, 6 \%, 8 \%$, and $10 \%$ wood charcoal percentage. From the results of testing the limits of soil consistency that can be used to calculate the soil liquid limit and increase the Berlin land boundary soil index becomes decreased. This reflects the existence of the soil. Taxable income from household prices to land and land. This can increase the shear strength of clay soil. By adding charcoal as a stabilizing material to the soil that can be weighed from the strong soil as a material to stabilize the collapse in the clay soil.
\end{abstract}

Keywords: Clay Lands, Direct Shear Test, Soil Stabilization, Cohesion

How to Cite: Rini \& Ardan, M. (2017), Analisa Nilai Kohesi dan Sudut Geser Tanah Lempung yang Distabilisasi dengan Arang Kayu, JCEBT (Journal of Civil Engineering, Building and Transportation). 1 (2): 105111. 
Rini \& Melloukay Ardan, Analisa Nilai Kohesi dan Sudut Geser Tanah Lempung yang Distabilisasi dengan

\section{PENDAHULUAN}

Tanah mempunyai peranan penting dalam suatu pekerjaan konstruksi, baik dijadikan bahan konstruksi maupun kuat dukung beban. Tanah lempung dengan indeks plastisitas tinggi sering dijumpai dalam pekerjaan konstruksi dilapangan, jenis tanah tersebut mempunyai kapasitas dukung yang rendah, dimana akan terjadi pengembangan volume apabila pori terisi air dan akan menyusut dalam kondisi kering. Hal ini sangat berbahaya karena tanah menjadi tidak stabil. Tanah yang tidak stabil tidak akan mampu mendukung suatu konstruksi pondasi bangunan dan akan mengakibatkan keruntuhan total pada bangunan tersebut. Oleh karena itu parameter kuat geser tanah diperlukan untuk menghitung daya dukung tanah atau untuk menghitung tegangan dorong dinding penahan tanah.

Stabilitasi tanah adalah pencampuran tanah dengan bahan tertentu yang berfungsi untuk memperbaiki sifat-sifat teknis tanah agar memenuhi syarat teknis tertentu. Proses stabilitas tanah juga dilakukan dengan pencampuran tanah dengan tanah lain untuk memperoleh gradasi yang diinginkan, atau pencampuran tanah dengan bahan tambah buatan pabrik, sehingga sifat-sifat teknis tanah menjadi lebih baik. Sehingga dapat merubah sifat-sifat teknis tanah seperti kapasitas dukung, kompresibilitas, permeabilitas, kemudahan dikerjakan, potensi pengembangan, dan sensifitas terhadap perubahan kadar air, maka dapat dilakukan dengan cara penanganan dari yang mudah seperti pemadatan sampai teknik yang lebih mahal seperti mencampur tanah dengan semen, kapur, abu terbang, injeksi semen (grouting). Stabilisasi dilakukan bila tanah dilokasi proyek tidak memenuhi syarat bila digunakan untuk rekayasa bengunan tertentu. Hal-hal yang perlu dipertimbangkan bila tanah tidak memenuhi syarat untuk pembangunan struktur adalah: Membongkar material dilokasi dan menggantikannya material yang sesuai; Merubah atau memperbaiki sifat-sifat ditempat, sehingga material tersebut memenuhi syarat.

Stabilisasi tanah dapat dibagi menjadi dua yaitu:

a. Stabilisasi mekanis

Stabilisasi mekanis atau stabilisasi mekanika dilakukan dengan cara mencampur atau mengaduk dua macam tanah atau lebih yang bergradasi berbeda untuk memperoleh material yang memenuhi syarat kekuatan tertentu. Pencampuran ini dapat dilakukan dilokasi proyek, dipabrik atau ditempat pengambilan bahan timbunan. Material yang telah dicampur ini, kemudian 
dihamparkan dan dipadatkan dilokasi Contoh-contoh bahan tambah adalah proyek. Stabilisasi mekanis juga dapat kapur, semen, portland, abuterbang dilakukan dengan cara menggali tanah (flyash), aspal (bitumen) dan lain-lain. buruk ditempat dan menggantinya dengan Stabilisasi dengan menggunakan material granorel dari tempat lain. Menurut lambe (1962) stabilisasi mekanis merupakan suatu proses yang menyangkut dua cara perubahan sifat-sifat tanah:

Penyusunan kembali partikelpartikel tanah, seperti contonya pencampuran beberapa lapisan tanah, pembentukan kembali tanah yang telah terganggu, dan pemadatan.

Penambahan atau penyingkiran partikel-partikel tanah. Sifat-sifat tanah tertentu dapat diubah dengan menambah atau menyingkirkan sebagian fraksi tanah. Biaya yang dikeluarkan untuk pekerjaan atau menyingkirkan ini umumnya sangant lebih rendah dibandingkan dengan metode stabilisasi yang lain. Contohnya, lempung berpasir dicampur dengan kerikil untuk memenuhi daya dukung tanah dasar dari proyek jalan tertentu.

b. Stabilisasi dengan menggunakan bahan tambah

Bahan tambah (additives) adalah bahan hasil olahan pabrik yang bila ditambahkan kedalam tanah dengan perbandingan yang tepat akan memperbaiki sifat-sifat teknis tanah, seperti kekuatan, tekstur, kemudahan dikerjakan (workability) dan plastisitas. bahan tambah atau sering disebut juga stabilisasi kimiawi bertujuan untuk memperbaiki sifat-sifat teknis tanah, dengan cara mencampur tanah, dengan cara mencampur tanah dengan menggunakan bahan tambah dengan perbandingan tertentu. Perbandingan campuran bergantung pada kulitas campuran yang diinginkan. Jika pencampuran hanya dimaksudkan untuk merubah gradasi dan plastisitas tanah, dan kemudahan dikerjakan, maka hanya memerlukan bahan tambah sedikit. Namun, bila stabilisasi dimaksudkan untuk merubah tanah agar mempunyai kekuatan tinggi, maka diperlukan bahan tambah yang lebih banyak. Material yang telah dicampur dengan bahan tembah ini harus dihamparkan dan dipadatkan dengan baik. Jenis tanah menentukan jenis bahan tambah yang cocok untuk stabilitasi. Beberapa pertimbangan yang perlu dilakukan dalam memilih tipe bahan tambah yang cocok adalah: Jenis tanah yang akan distabilisasi; Jenis struktur yang distabilisasi; Ketentuan kekuatan tanah yang harus dicapai; Tipe dari perbaikan tanah yang diinginkan; Dana yang tersedia; Kondisi lingkungan. 
Sifat mekanis tanah yaitu sifat tanah jika memperoleh pembebanan dan digunakan sebagai parameter dalam perencanaan pondasi. Dalam hal ini penelitian yang dilakukan untuk mengetahui sifat mekanis tanah adalah kuat geser langsung (direct shear test).

\section{METODE PENELITIAN}

Metode penelitian yang dilakukan untuk menambah kuat dukung tanah adalah dengan mengurangi atau menghilangkan sifat-sifat teknis tanah yang kurang menguntungkan dengan cara mencampur tanah dengan bahan kimia arang dengan persentase penambahan $4 \%$, $6 \%, 8 \%, 10 \%$. Adapun penelitian yang dilakukan untuk mendukung hasil analisa dilaboratorium dilakukan dengan uji secara fisik yaitu dengan dilakukannya uji batas atterbeg, dan uji secara mekanis dengan dilakukanya uji kuat geser langsung (direct shear test). Adapun bagan alir dari penelitian ini dapat dilihat dari Gambar 1.

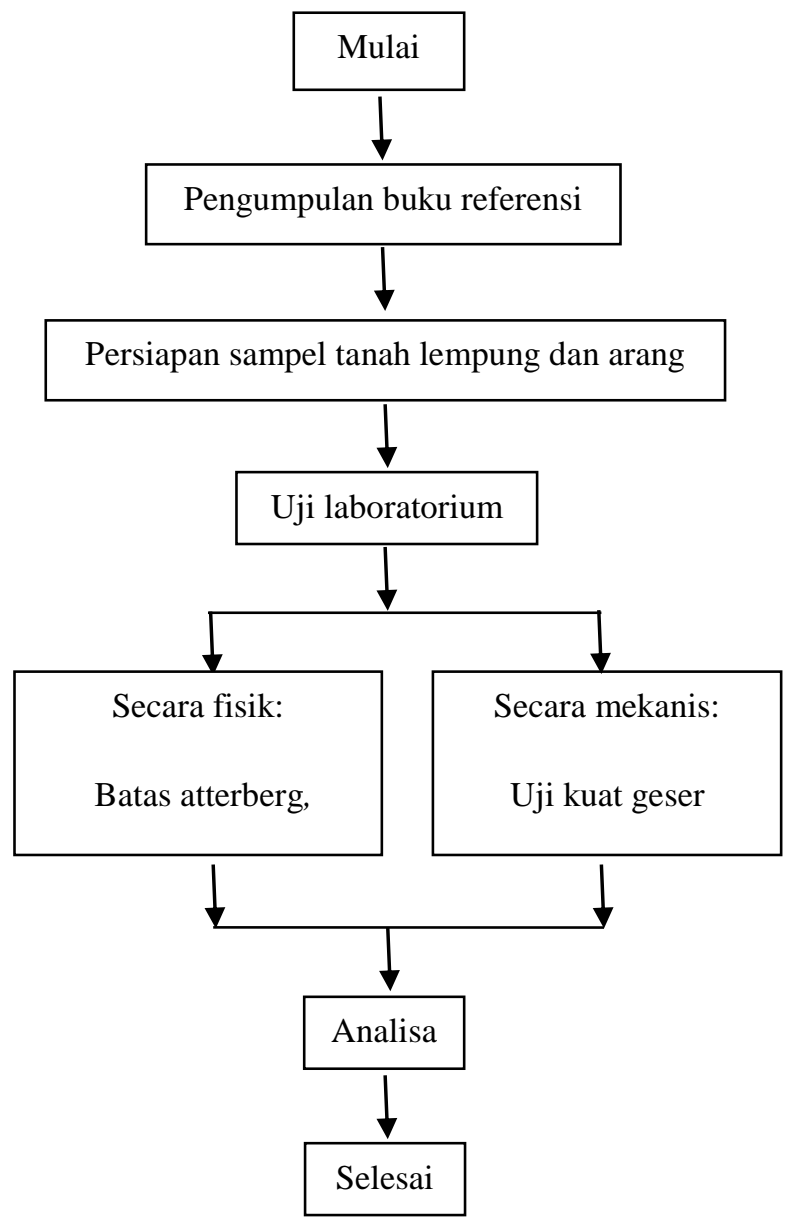

Gambar 1. Bagan Alir Penelitian

HASIL DAN PEMBAHASAN

\section{Analisa Batas-Batas Atterberg}

Batas cair dan batas plastis adalah kadar air tanah dimana tanah lempung berada dalam keadan batas cair dan keadaan plastis. Dengan melakukan penambahan arang kayu pada tanah lempung nilai-nilai batas cair, batas plastis, dan indeks plastis mengalami perubahan. Gambar 2, Gambar 3 dan Gambar 4 masing-masing menunjukan hubungan arang dengan tanah lempung terhadap nilai batas cair, batas plastis, indeks plastis. 


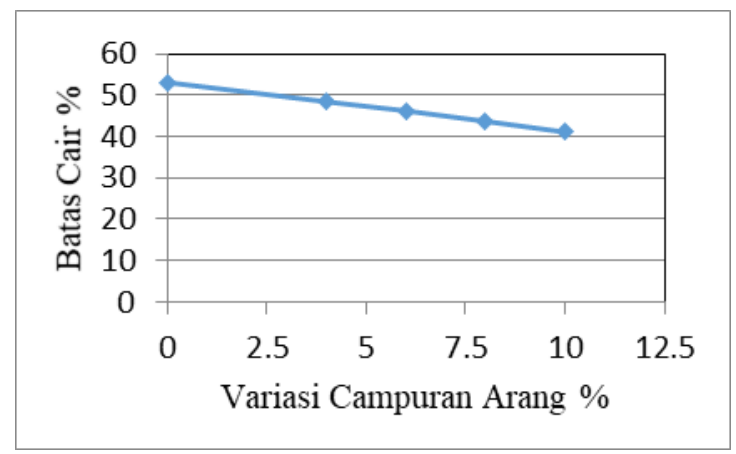

Gambar 2. Hubungan Penambahan Arang Terhadap Batas Cair

Dari Gambar 2 dapat dilihat terjadi penurunan nilai batas cair pada setiap variasi penambahan arang. Seperti pada penambahan arang sebesar $4 \%$ batas cairnya adalah 53,11 , penambahan arang $6 \%$ adalah 46,23 , penambahan arang $8 \%$ adalah 43,7 , penambahan $10 \%$ adalah 41,1 .

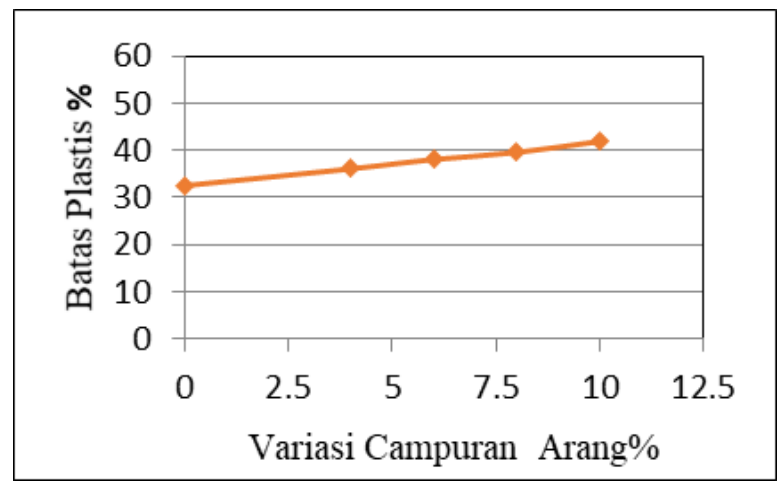

Gambar 3. Hubungan Penambahan Arang Terhadap Batas Plastis

Gambar 3 menunjukan bahwa terjadi kenaikan nilai batas plastic pada setiap variasi penambahan arang. Seperti pada penambahan arang sebesar $4 \%$ batas cairnya adalah 32,55 , penambahan arang $6 \%$ adalah 36,11 , penambahan arang $8 \%$ adalah 39,58, penambahan $10 \%$ adalah 41,9 .

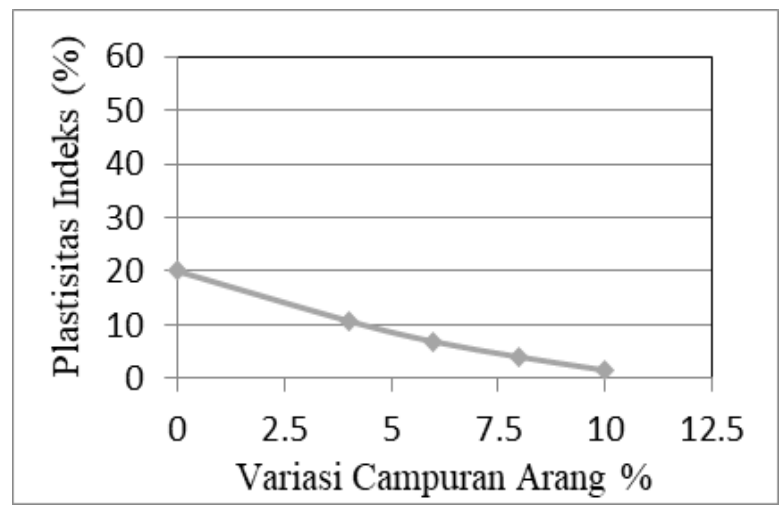

Gambar 4. Hubungan penambahan arang terhadap plastic index

Gambar 4 menunjukan bahwa terjadi penurunan nilasi plastic index pada setiap variasi penambahan arang seperti pada penambahan arang sebesar $4 \%$ plastic index adalah 20, penambahan arang 6\% adalah 10,76, penambahan arang $8 \%$ adalah 4,05 , penambahan $10 \%$ adalah 1,58 .

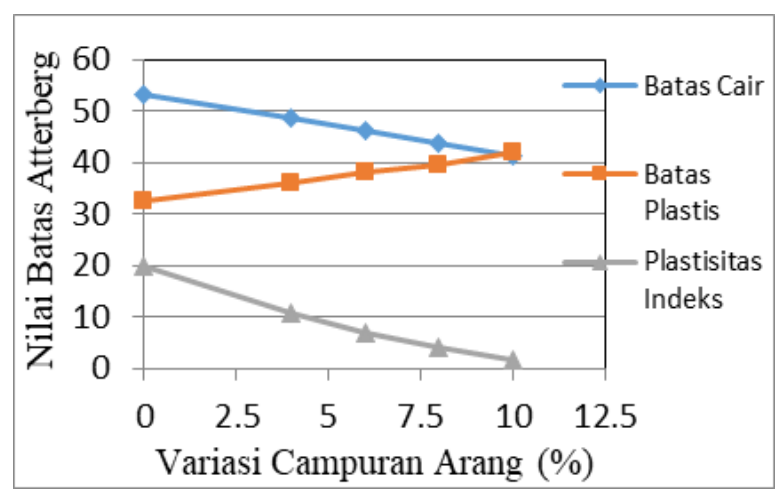

Gambar 5. Nilai Batas Atterberg pada Variasi Campuran Arang

Dari Gambar 5 di atas menunjukan bahwa penambahan arang menyebabkan batas cair pada tanah lempung mengalami penurunan, batas plastis mengalami kenaikan sehingga menyebabkan indeks 
plastis mengalami penurunan hal ini menunjukan bahwa tanah lempung mengalami perbaikan sifat.

\section{Analisa Kuat Geser Langsung}

Berdasarkan hasil uji kuat geser langsung lempung yang distabilisasi dengan campuran arang dengan variasi campuran $0 \%, 4 \%, 6 \%, 8 \%, 10 \%$. Pada Gambar 6, tampak nilai kohesi mengalami penurunan pada penambahan $4 \%$ kohesinya $0,3 \mathrm{Kg} / \mathrm{Cm}$, penambahan $6 \%$ nilai kohesi menjadi $0,4 \mathrm{Kg} / \mathrm{Cm}$, pada $8 \%$ nilai kohesi menjadi $0,5 \mathrm{Kg} / \mathrm{Cm}$ dan penambahan $10 \%$ kohesi menjadi 0,6 $\mathrm{Kg} / \mathrm{Cm}$.

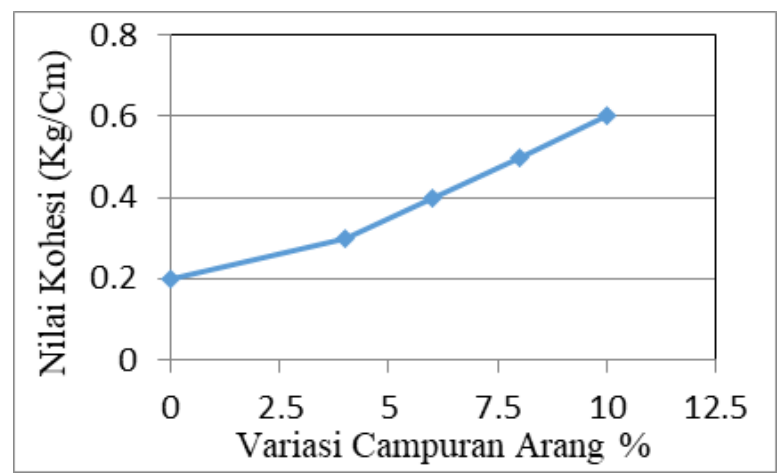

Gambar 6. Hubungan Nilai Kohesi Dengan Variasi Campuran Arang

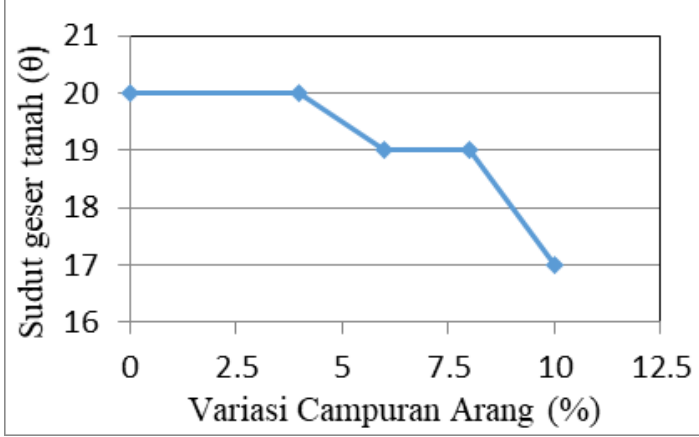

Gambar 7. Hubungan Sudut Geser Tanah

Dengan Variasi Campuran Arang
Berdasarkan hasil uji kuat geser langsung lempung yang distabilisasi dengan campuran arang dengan variasi campuran $0 \%, 4 \%, 6 \%, 8 \%, 10 \%$. Dapat dilihat Gambar 7 menunjukkan penurunan pada sudut geser tanah. Pada penambahan $4 \%$ sudut geser tanahnya $20^{\circ}$, penambahan $6 \%$ sudut geser tanahnya $19^{\circ}$, pada $8 \%$ sudut geser tanahnya $19^{\circ}$ dan penambahan $10 \%$ sudut geser tanahnya $17^{\circ}$.

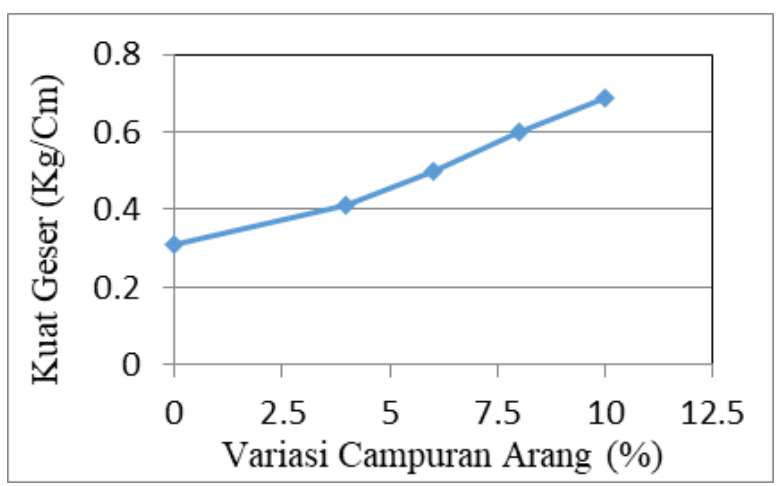

Gambar 8. Hubungan Kuat Geser Tanah Dengan Variasi Campuran Arang

Berdasarkan hasil uji kuat geser langsung lempung yang distabilisasi dengan campuran arang dengan variasi campuran $0 \%, 4 \%, 6 \%, 8 \%, 10 \%$. Dapat dilihat pada Gambar 8 menunjukkan kenaikkan pada kuat geser tanah. Pada penambahan 4\% kuat gesernya sebesar $0,41 \mathrm{Kg} / \mathrm{Cm}$, penambahan $6 \%$ kuat gesernya sebesar $0,50 \mathrm{Kg} / \mathrm{Cm}$, pada $8 \%$ kuat gesernya sebesar $0,60 \mathrm{Kg} / \mathrm{Cm}$ dan penambahan $10 \%$ kuat gesernya sebesar $0,69 \mathrm{Kg} / \mathrm{Cm}$ 


\section{SIMPULAN}

Berdasarkan hasil pengujian atterberg yang dilakukan pada tanah lempung yang diberi penambahan campuran arang dengan persentase 4\%, $6 \%, 8 \%, 10 \%$ dapat menurunkan nilai batas cair tanah dan menaikkan batas plastis tanah sehingga indeks plastis tanah menjadi menurun. Hal ini menunjukkan adanya perbaikkan sifat tanah. Berdasarkan hasil uji kuat geser langsung lempung yang distabilisasi dengan campuran arang dengan variasi campuran $0 \%, 4 \%, 6 \%, 8 \%, 10 \%$ terjadi penurunan nilai kohesi. Pada penambahan $4 \%$ nilai kohesinya $0,3 \mathrm{Kg} / \mathrm{Cm}$, penambahan $6 \%$ nilai kohesi menjadi $0,4 \mathrm{Kg} / \mathrm{Cm}$, pada $8 \%$ nilai kohesi menjadi $0,5 \mathrm{Kg} / \mathrm{Cm}$ dan penambahan $10 \%$ nilai kohesi menjadi 0,6 $\mathrm{Kg} / \mathrm{Cm}$. Berdasarkan hasil uji kuat geser langsung lempung yang distabilisasi dengan campuran arang dengan variasi campuran $0 \%, 4 \%, 6 \%, 8 \%, 10 \%$ nilai sudut geser tanah mengalami penurunan seperti pada penambahan $4 \%$ sudut geser tanahnya $20^{\circ}$, penambahan $6 \%$ sudut geser tanahnya $19^{\circ}$, pada $8 \%$ sudut geser tanahnya $19^{\circ}$ dan penambahan $10 \%$ sudut geser tanahnya $17^{\circ}$

\section{DAFTAR PUSTAKA}

ASTM. (1981). Annual Book of ASTM", Philadelphia, USA.

Bowles, J.E. (1991), "Sifat-Sifat Fisis Tanah dan Geoteknis Tanah", Erlangga, Jakarta.

Das, B.M. (1985). "Principles of Geoteknik Engineering", PWS Publisher, Boston.

Das, B.M. Noor. E. Mochtar, I.B. (1995). "Mekanika Tanah (Prinsip-prinsip Rekayasa Geoteknik) Jilid 1", Erlangga, Jakarta.

Hardiyatmo, H.C. (2007), Mekanika Tanah II, edisi ke IV, Gadjah Mada University Press, Yogyakarta.

Hardiyatmo, H.C. (2010). Mekanika Tanah I edisi ke V, Gadjah Mada University Press, Yogyakarta. https://id.m.wikipedia.org/wiki/Arang

Wesley, L.D. (1994), “Mekanika Tanah”, (Cetakan ke VI), Badan penerbit Pekerjaan umum, Jakarta. 